\title{
VICISITUDES CON/EN LA DEUTSCHE SPRACHE. UN ENSAYO AUTOBIOGRÁFICO ACERCA DE LAS IGUALDADES Y LAS DIFERENCIAS
}

\section{Vicissitudes with / in the deutsche Sprache. An autobiographical essay about equalities and differences}

\author{
Pablo de Marinis* \\ * Instituto de Investigaciones Gino Germani, Universidad de Buenos Aires, CONICET \\ pablodemarinis@gmail.com
}

\section{Palabras clave \\ Lenguaje Idioma alemán Traducción Sociología Ensayo autobiográfico}

\section{Keywords}

Language German language Translation Sociology Autobiographical essay

\begin{abstract}
$\underline{\text { Resumen }}$
El artículo narra en clave autobiográfica mi experiencia como estudiante de doctorado inmigrante (no "viajero" ni "exiliado") en Alemania, poniendo especial énfasis en las diversas etapas que marcaron el proceso de aprendizaje de la lengua alemana. La primera etapa que describo es aquella en la que seguí un curso universitario formal e institucionalizado de alemán como lengua extranjera. Luego, explico los complejos procesos por los cuales me convertí en un lector y en un traductor (no sólo de textos, sino de sentidos, experiencias y vivencias). Finalmente, narro las peripecias vividas en la escritura de mi tesis doctoral. Además, articulo todas aquellas experiencias con unas reflexiones más amplias acerca del significado del lenguaje y la traducción, así como acerca de la igualdad y la diferencia, en la especificidad de las ciencias sociales y más allá de ellas.
\end{abstract}

\section{Abstract}

The article narrates in autobiographical terms my experience as a PhD immigrant student (not a "traveler" or "exiled") in Germany, placing special emphasis on the various stages that marked the learning process of the German language. The first stage that I describe is that in which I followed a formal and institutionalized university course to learn German as a foreign language. Then, I explain the complex processes through which I became a reader and a translator (not only of texts, but of senses and (life) experiences). Finally, I narrate the (unexpected) events related to the writing of my doctoral dissertation. In addition, I articulate all those experiences with broader reflections about the meaning of language and translation, as well as about equality and difference, specifically in the social sciences and beyond them.

De Marinis, P. (2018). Vicisitudes con/en la deutsche Sprache. Un ensayo autobiográfico acerca de las igualdades y las diferencias. Papeles del CEIC. International Journal on Collective Identity Research, vol. 2018/2, papel 200, CEIC (Centro de Estudios sobre la Identidad Colectiva), UPV/EHU Press, http://dx.doi.org/10.1387/pceic.19865

Recibido: 06/2018; Aceptado: 07/2018

\section{INTROITO}

No pretendo cultivar una supuesta profesión de fe postmoderna. Tampoco me anima el propósito de hacer un gratuito elogio de las (otra 
vez: supuestas) bondades de la "vida líquida". Pero hay algo que debo confesar desde el comienzo: no soy proclive a hacer rígidas planificaciones a largo plazo en casi ningún plano, aspecto, faceta o dimensión de mi vida. Tampoco vivo estrictamente al día, pues no podría soportarlo. Pero lo cierto es que, de cara al futuro, apenas me permito delinear algunos proyectos más o menos amplios, generales $(y$, por ende, borrosos), movilizar ciertos deseos y acciones en lo que supongo que podría apuntar en esa dirección, y no mucho más. Future will tell.

Mi (decididamente: ya no breve) experiencia vital me indica que los contextos, las condiciones, y junto a ellas las chances de realizar los propios objetivos, suelen cambiar de manera abrupta, de un momento a otro. De tal forma, los planes que, así sea de manera esquemática, se habían esbozado antes, luego naufragan o deben reformularse. No sé si con esta actitud intento sintonizarme con los rasgos generales de nuestra época histórica, tan proclive a la movida espasmódica y de corto plazo. O si simplemente me hago cargo, con una resignación más específica y situada, del lugar y del momento exactos en los que me toca vivir. En efecto, vivo en el Sur del Sur, región de históricas y variadas volatilidades, justo cuando, con aval electoral de buena parte de la población, los dueños de los negocios financieros ${ }^{1}$ han asumido sin mediación alguna el timón formal de las instituciones del Estado, acentuando (como buenos financistas que son) los rasgos de vértigo, inestabilidad y provisoriedad que todo ya tenía de por sí, por pura condición de época.

Pero no siempre viví en el Sur del Sur. Por fortuna, por azar o por necesidad, acaso por todo eso junto, transcurrí casi 10 años de mi vida en el Norte. Precisando un poco más: la mayor parte de ese tiempo en el "Norte del Norte", en Alemania, y luego 2 años también en el Norte, pero "un poco menos Norte que el Norte del Norte", en España. En ese lapso realicé muy variadas actividades y tuve incontables experiencias, entre ellas una tesis de doctorado en sociología. Al cabo de esa década, en una jugada que ahora juzgo como bastante osada, que tuvo muchos más rasgos de "racionalidad con arreglo a valores" que de "racionalidad con

\footnotetext{
1 "La raza descarada de nuestros dueños", los llamó con su habitual corrosividad Gilles Deleuze (1995: 284).
} 
arreglo a fines", regresé a mi ciudad natal, Buenos Aires, y aquí sigo, hasta nuevo aviso².

Dejando de lado algunos viajes por trabajo o turismo, y que en comparación con aquella década han sido muy breves, ya no he vuelto a emigrar. Sin embargo (sé que va a sonar cursi lo que estoy por afirmar, pero asumo con gusto el riesgo), debo decir que aquella experiencia ha dejado una huella indeleble en lo que hoy soy. Pero más interesante para relatar en una publicación de ciencias sociales sería decir que esa huella también ha quedado marcada en mi trabajo como sociólogo, en el tipo de miradas que lanzo (o pretendo lanzar) sobre el mundo social. Justamente a narrar algunos recuerdos (sesgados, selectivos y exagerados, como todo recuerdo) de aquella experiencia, así como a reflexionar acerca de la lengua alemana y lo que su aprendizaje me deparó, dedicaré las páginas que siguen. Avanzaré, entonces, en un ejercicio de escritura que, siguiendo una sugerencia de un dossier de un número anterior de esta revista donde participaron algunos y algunas colegas del campo de las ciencias sociales en/sobre/desde América Latina, localizaré "a medio camino entre quehacer académico e introspección biográfica" (Gatti, Irazuzta, Martuccelli, 2015: 1)³.

\section{NI VIAJERO NI EXILIADO: MIGRANTE}

En consonancia con lo que ya comenté acerca de las formas a través de las que suelo "conducir mi vida", no había planificado con mucha antelación la crucial decisión de expatriarme por un lapso indefinido, con pasaje sólo de ida, Todo aquello se desencadenó en forma más bien urgente en 1991, a poco de graduarme en sociología en la Facultad de Ciencias Sociales de la Universidad de Buenos Aires.

Quisiera contextualizar con mayor detalle aquella fuerte jugada migratoria. Pertenezco con no poco orgullo a las primeras generaciones de egresados y egresadas de esa carrera que empezaron a formarse luego de nuestra última dictadura militar (la de 1976-1983), en una

\footnotetext{
${ }^{2}$ Así podría calificar mi retorno a Buenos Aires, para empezar a despuntar mis persistentes e incurables vicios weberianos.

3También en aquella publicación, Arocena llamó a su texto "autoficción" (2015). Al parecer, al presente ensayo también se lo podría calificar como "autoetnografía". Véanse por ejemplo Feliu (2007), o Blanco (2012), que explican de qué se trata ese tipo de escritura.

${ }^{4}$ Vuelvo a jugar con términos weberianos, esta vez con la sugerente (iy tan foucaultiana también!) categoría de Lebensführung.
} 
universidad que por entonces era tan excitante y estimulante en términos intelectuales y políticos como precaria en sus finanzas y su infraestructura. Así, a inicios de los '90, jóvenes graduados y graduadas fuimos arrojados literalmente a la calle, en un contexto económico posthíperinflacionario ${ }^{5}$ y de grave crisis social, con un diploma bajo el brazo considerado por todo el mundo como "muy interesante" ${ }^{6}$ pero a la vez con posibilidades de inserción muy inciertas en el mercado de trabajo.

Luego de nuestra graduación, algunos compañeros y compañeras de la licenciatura en sociología ensayaron con diversa suerte inserciones laborales en dependencias estatales, en ONG y otras organizaciones, en los pocos centros (privados, con financiamiento internacional) de investigación social que había en ese momento, o en el más rentable mundo de las consultoras de opinión pública y marketing. Así, asumieron de manera decidida una práctica de la sociología como "profesión", o una identidad de lo que luego se llamaría "analistas simbólicos"7.

Pero había también algunos menos quienes, como yo, nos empecinábamos en iniciar un camino más genuinamente "académico". Para esta subtribu de la sociología académica, que yo integraba y aún me empecino en seguir integrando, las posibilidades estaban por entonces en el país mucho más cerradas que lo que lo estarían apenas dos décadas después ${ }^{8}$. En efecto, en aquellos años, la oferta local de

\footnotetext{
${ }^{5}$ Haber pasado por una experiencia híperinflacionaria, evidentemente, ha dejado más marcas en nuestras biografías que las que estamos dispuestos a admitir. Mi compatriota y coetáneo Francescutti explica en estos términos las razones de su salida de Argentina, más o menos contemporánea a la mía (aunque en su caso hacia España): "yo era uno más en la estampida de graduados sin futuro, profesionales desesperados y personas arruinadas por la hiperinflación que acabó con el gobierno de Alfonsín" (2015:4).

${ }^{6}$ Quienes hemos estudiado sociología, o filosofía, o antropología, u otras disciplinas vecinas, hemos experimentado más de una vez (en eventos sociales en los cuales se nos interroga acerca de nuestra ocupación) que nuestros interlocutores caractericen nuestras carreras como "muy interesantes", afirmando además que les hubiera gustado estudiarlas, pero que finalmente optaron por otra cosa, como administración de empresas, derecho, o alguna otra a la que suponen con destinos laborales mucho más previsibles, imaginables o tangibles.

${ }^{7}$ Todo esto lo explica muy bien Blois en sus diferentes publicaciones, por ejemplo 2014. Véase también 2018 , donde toma un periodo más extenso.

${ }^{8}$ Beigel, Gallardo y Bekerman (2018) ponen en una perspectiva histórica de largo plazo las transformaciones de los últimos años del campo académico argentino en términos de su institucionalización, profesionalización e internacionalización. Otro trabajo reciente (Blanco y Wilkis, en prensa), más focalizado, exhibe los patrones de internacionalización de la sociología argentina, analizando CV de graduados y graduadas de sociología de la
} 
estudios de posgrado en ciencias sociales era entre magra e inexistente, lo mismo que el sistema público de becas. Por demás, en un contexto como en el de mi Facultad, donde predominaban las plazas a tiempo parcial, había casi nulas chances de ingresar a la docencia e investigación universitaria y de (cuestión no menor) poder vivir de ello.

En mi caso y en el de algunos otros compañeros y compañeras generacionales, entonces, objetivamente hablando, se empezaba a perfilar la opción por una emigración. Algo a lo que yo, además, le agregaba mis propias motivaciones subjetivas, sobre las que luego algo diré. Por todas estas razones juntas, mi experiencia migratoria terminó siendo muy distinta a la de muchos de mis profesores y profesoras de la universidad, quienes en buena medida habían sido protagonistas de los exilios políticos de los 60 y $70^{9}$. Gracias a esas migraciones forzadas ${ }^{10}$, habían logrado salvar sus vidas en peligro y de ese modo también reconducir sus trayectorias intelectuales y académicas ${ }^{11}$.

Pero el mío tampoco sería un "viaje", en el sentido de los habituales "viajes de iniciación" a ciertos lugares tenidos por "mecas culturales" en ciertos momentos históricos, que pueden encontrarse en numerosas biografías de científicos, intelectuales y artistas de países periféricos, y no sólo periféricos ${ }^{12}$. Esos viajes, por lo general, suelen (o solían) ser más o menos breves, de unos pocos meses/años de duración. Además, tienen (o tenían) más bien la forma de la estancia en uno o varios países extranjeros (por un cierto plazo, para luego regresar a casa) que de la emigración voluntaria por un periodo largo de tiempo, como fue en mi

Universidad de Buenos Aires, con título de doctorado, y con actividad en universidades y centros de investigación (de más no está mencionar que integro esa muestra).

${ }^{9}$ En tan impecable como económica prosa, Irazuzta compara a exiliados (como sus profesores, y los míos) y migrantes (como él y yo): "el del exilio es un sujeto de estructuras, el de la emigración parece que lo fuera de agencia. Al primero nos lo representamos como habitante incómodo de tiempos políticos, en tanto que al segundo como agente inquieto de momentos económicos" (2015: 10-11).

${ }^{10}$ En algunos casos, no se trató de destierros en sentido estricto, sino del llamado "exilio interno", consistente en mudarse hacia otras zonas del país menos visibles o expuestas que Buenos Aires a los ojos de los tiranos de turno, y/o en cambiar de ocupación hacia otros ámbitos laborales menos comprometidos que las siempre politizadas e ideologizadas ciencias sociales.

${ }^{11}$ Recién regresaron al país (y/o volvieron a pisar la universidad) a partir de 1983/84, apenas se estaba iniciando nuestra "transición democrática".

${ }^{12}$ Véase la preciosa compilación, precedida por un incisivo estudio previo, que hace Jitrik (1969) de relatos de viajes a Europa de escritores argentinos (Sarmiento, Borges, Arlt, Cortázar, Victoria Ocampo, y varios más). 
caso, o el destierro forzado o el exilio interno, como en el de mis profesores y profesoras de la universidad ${ }^{13}$.

Tanto se iba perfilando entonces mi emigración que finalmente se concretó, apenas un mes después de graduarme. Así, a las dificultades objetivas e institucionales ya mencionadas para proseguir algo que se pareciera a una "carrera académica" en mi país tal como yo me la imaginaba ${ }^{14}$, se le sumaron una serie de "circunstancias personales", combinadas con una fuerte inclinación, interés, o gusto que yo ya venía cultivando por la "cultura alemana", en especial por los libros de Max Weber y Jürgen Habermas y por las películas de Werner Herzog y Rainer Fassbinder ${ }^{15}$. Todo esto, en dosis variadas de cada cosa, terminó llevándome a Alemania, adonde podría decirse que me fui a vivir, en primer lugar, y a seguir estudiando, también ${ }^{16}$.

Visto con mis ojos de hoy, pero también comparándolas con las características que asumirian pocos años después estas "estancias de formación de posgrado" en sociólogos y sociólogas de generaciones posteriores (a quienes alenté y sigo alentando fervientemente a que

\footnotetext{
${ }^{13}$ Para poner las cosas en un contexto más amplio, podríamos plantearnos preguntas de imposible respuesta: ¿qué hubiera sido de las ciencias sociales y humanas sin estos exilios, viajes y migraciones? ¿Cómo hubieran lucido las obras de Talcott Parsons, Robert Park y William Thomas si no hubieran pasado por su viaje-experiencia en Alemania? ¿cómo hubieran seguido sus derroteros intelectuales los miembros de la Escuela de Frankfurt sin sus exilios, sobre todo a EE.UU.? ¿y los científicos sociales del Cono Sur sin la generosa acogida que les brindó por ejemplo México? De los abundantes trabajos que se ocupan de lo que fue (y no de lo que podría haber sido) a partir de viajes y exilios de personajes de las ciencias sociales y humanas, por razones de espacio citaré sólo dos: Schrecker (2010) y Offe (2006).

${ }^{14}$ Realmente me la imaginaba, porque tampoco conocía muy bien, de primera mano, en qué consistía esa posibilidad. Es que mis muchos de mis maestros y maestras, al regresar al país, habian asumido más bien el perfil de los "intelectuales críticos", que alternaban la docencia con otras actividades, y no el de los profesores-investigadores de tiempo completo, como los que habría de conocer luego en Alemania, o como los había ya en otros países latinoamericanos con campos académicos más consolidados, como Brasil o México, que habian sufrido comparativamente mucho menos que nosotros las recurrentes rupturas institucionales, del pais y de la universidad.

${ }^{15}$ La lista de "atracciones culturales" que yo asociaba con Alemania no se restringía, por cierto, al cine y a las ciencias sociales y humanas. Podía ampliarse a la música (desde Beethoven a Kraftwerk), a la literatura (desde Goethe hasta Grass pasando por Brecht) e incluso a la Bundesliga y a los deliciosos embutidos.

${ }^{16}$ Si la persona que protagonizó aquellas "circunstancias personales" alguna vez llegara a leer este artículo ( $y$, dada su ocupación, es probable que así sea), quizás podría sentirse decepcionada por la forma tan despojada en que la presento. De todos modos, quiero que escuche de mí lo que seguramente ya sabe: que fue fundamental en aquella tan relevante decisión de emigrar que tomé por entonces.
} 
hagan una experiencia de esta índole), las mías eran unas condiciones atravesadas de cabo a rabo por una enorme precariedad: sin una plaza doctoral asegurada, sin una beca que financiara mis estudios, sin una densa red de capital social en el mundo académico alemán, con unos conocimientos de la lengua que yo suponía básicos pero que en realidad eran bastante menos que eso, y con dinero apenas suficiente como para sostenerme económicamente durante un mes, a lo sumo.

Pero, a decir verdad, a aquel irresponsable e impetuoso joven de 23 años no le preocupaban demasiado todas estas cuestiones. Así, percibía que en mi vida realmente todo estaba por hacerse (lo cual era estrictamente cierto), y por añadidura mi partida se había visto favorecida por la escasez de ataduras que yo experimentaba por entonces en Buenos Aires: ni una relación de pareja que interrumpir o replantear, ni la preocupación por la salud de progenitores ancianos (los míos todavía no lo eran) o por el desarraigo de los hijos (en ese entonces no los tenía), ni un gran puesto de trabajo ni una casa propia que abandonar. En suma, aquel sociólogo recién graduado, migrante en ciernes, era un individuo tremendamente autonomizado (atravesado, como siempre es el caso, por mil determinaciones sociales, pero autonomizado al fin, quizás asumiendo incluso algunos rasgos anómicos).

\section{El DESEMBARCo (O EL ATERRIZAJE EN UNA EXTRAÑA TIERRA CONOCIDA)}

El desembarco/aterrizaje en Alemania fue ciertamente abrupto y sin paracaídas. Aquello supuso un aprendizaje acelerado y una intensa socialización y (re)socialización que, desde luego, no sólo habría de restringirse a los avatares académicos. Aunque, por las obvias razones del contexto donde estas reflexiones van a aparecer (una revista de ciencias sociales), será acerca de estos últimos donde pondré el mayor énfasis.

Muy diversas cosas llamaron mi atención apenas llegar a Alemania, donde tampoco había estado previamente como turista: desde las formas que asumen las conversaciones (con menos superposición de voces y a un volumen promedio algo más bajo que el de aquí ${ }^{17}$,

${ }^{17}$ Creo que, a esta altura del relato, debería quedar claro que mi "aqui", hoy, es claramente Buenos Aires. En ese sentido, es notable el contraste con lo que plantea Gatti, quien en base a la forma que ha tomado su recorrido biográfico-académico tiene mucho más margen de maniobra que el que yo tengo ahora para jugar con la "ambigüedad de los 
obviamente comparando espacios sociales similares, por ejemplo, un grupo de estudiantes preparando un examen universitario), hasta la distancia que se mantiene entre los cuerpos en el transporte público (mayor que aquí, evitando en lo posible todo roce), pasando por el uso infrecuente del tuteo (limitado sólo a amigos) y del generalizado tratamiento de usted (incluso entre gente joven), o las formas en que se intercambian las miradas en la calle (nunca directo a los ojos), y mil cuestiones más. Me llevó un cierto tiempo, más o menos largo, interpretar de manera no prejuiciosa (esto es, lo menos etnocéntrica posible) lo que cada una de estas manifestaciones podría significar. De ese permanente y casi obligado ejercicio de la comparación y el contraste resultó también una impresionante objetivación (y una relativización, una des-absolutización, una des-exclusivización, o no sé cómo llamarla) del (por decirlo rápido) "bagaje cultural” que yo traía.

De todos modos, y amén de lo recién comentado (que podría extenderse a muchas otras situaciones, gestos, usos, costumbres, modos, giros, etc., dentro del pequeño mundo de la universidad, pero también en el más amplio "mundo de la vida"), ya desde el comienzo no me resultó aquella una experiencia de la total ajenidad, de la permanente perplejidad y de la absoluta incomprensión. Por una parte, antes de llegar yo ya "sabía" de Alemania ${ }^{18}$ mucho más que lo que se "sabía" allí de Argentina ${ }^{19}$. Por otra parte, e independientemente del conocimiento que yo disponía sobre "Alemania", y que había adquirido durante años ${ }^{20}$, después de todo yo traía del "Sur del Sur" un bagaje de referencias culturales más o menos compartidas con ese lugar al cual estaba recién llegando, y que

adverbios" de lugar (2015: 3). Por demás, y para seguir dialogando con aquel número monográfico de Papeles del CEIC donde aparece el artículo de Gatti y varios más que estoy citando ahora, y porque tiene relación con el problema del "aquí" y el "allí", aprovecho para incluirme en una de las categorias de la taxonomía que elaborara Martuccelli (2015) para investigadores sociales que trabajan en el campo de la sociología sobre América Latina: los "formados en el exterior" y que luego regresamos a casa. Y, finalmente, no quiero dejar de recuperar la idea de "frontera" que trae Castillejo Cuéllar (2015), porque hace estallar por el aire la polaridad del "aquí" y el "allï".

${ }^{18} \mathrm{Al}$ menos de su historia y de su cultura, aunque pronto habria de comprobar que sabia mucho menos de los usos y costumbres de la vida cotidiana.

${ }^{19} \mathrm{~A}$ excepción de ciertos círculos ilustrados, informados y politizados que podian localizarla, real, simbólica y también imaginariamente en Lateinamerika, que además tenían bien claro que no se encuentra en el Caribe ni es una provincia de Brasil, que no tiene tasas de analfabetismo del $99 \%$ y que, en algunas de sus regiones, tiene temperaturas que incluso pueden no ser tórridas.

${ }^{20}$ y sin proponérmelo de manera deliberada, esto es, asistemáticamente, leyendo ciertos libros, viendo ciertas películas y escuchando ciertas músicas. 
tienen que ver con constructos de enorme densidad histórica como "Occidente", "modernidad", “cristianismo", "vida urbana", etc. ${ }^{21}$. Por todo esto, y aun cuando al inicio de mi experiencia manejaba todavía muy pobremente la lengua, jamás experimenté esa sensación de no poder hacer encajar cada nueva experiencia, de alguna manera, en un stock de otras experiencias ya vividas/sentidas (y no sólo leídas en libros o vistas en películas).

La aventura que fui emprendiendo, en sucesivos y no lineales pasos, con el aprendizaje, adquisición, incorporación, uso (y ya se verá más abajo qué otros sustantivos podrían agregarse) de la lengua alemana sería de enorme importancia, no sólo para la consecución de mis propósitos estrictamente académicos, sino para mi vida en general, incluso hasta hoy. Dedicaré el resto del artículo a rememorar algo de todo aquel proceso y a extraer, cuando resulte posible, algunas conclusiones que puedan decir algo, también, del presente desde el cual escribo ${ }^{22}$.

\section{ODISEA DE LA LENGUA ALEMANA}

Por razones prácticas, dividiré el relato que sigue en fases o etapas, aunque en la realidad no se hayan dado de ese modo, de manera lineal y sucesiva, sino con numerosos solapamientos, avances, retrocesos, marchas y contramarchas. Antes de empezar con la descripción de estas etapas, quisiera decir algo breve acerca de mi actitud básica respecto del proceso que estaba por iniciar, y acerca de las condiciones iniciales

\footnotetext{
${ }^{21}$ Me parece importante que no se malinterprete lo que acabo de expresar. De allí que deba ofrecer algunas explicaciones adicionales: tenía ya entonces (y sigo teniendo ahora, con muchos más elementos de juicio en mano que antes) bastantes certezas acerca de que la idea de "modernidad" se aplana y se empobrece de la mano de declinaciones unívocas o unilaterales como las que a menudo se nos ofrecen; que también el concepto de "Occidente" debe ser sometido a una cuidadosa deconstrucción; que "cristianismo" subsume experiencias religiosas pero sobre todo consecuencias prácticas de muy variada significación y alcance; que "vida urbana" remite aqui y allá a cuestiones bien diferentes además de a "mucha gente viviendo junta en poco espacio", y así sucesivamente.

${ }^{22}$ Soy apenas un sociólogo castellanoparlante que trata de reflexionar acerca de las experiencias de su aprendizaje de la lengua alemana (y sus consecuencias). De allí que posiblemente, en lo que sigue, cometa algunos errores terminológicos. Por lo que me veo obligado a hacer lo mismo que hizo Weber en la introducción a sus ensayos de sociología de la religión, donde se atajó y abrió el paraguas ante posibles críticas advirtiéndole a sinólogos, egiptólogos, semitistas e indólogos que en esas páginas no iban a encontrar nada que ellos no supieran, y que sólo esperaba no decir nada que sea materialmente falso. Precisamente eso mismo quisiera decirle ahora a expertos y expertas en filología, lingüistica y traducción que pudieran por casualidad toparse con el presente artículo.
} 
que tenía para ello. Esto es: que me propuse de entrada aprender "de verdad" el alemán. El alcance de esa "verdad" lo explicaré en lo que sigue.

\subsection{Las condiciones iniciales}

Cuando llegué a Alemania, contaba en mi stock de idiomas con: 1) unos cuantos años de estudio formal y sistemático de inglés que me permitían hablarlo, leerlo y escribirlo con cierta dignidad; 2) un francés un poco amañado aprendido en los 5 años de escuela secundaria (pero que al menos me alcanzaba para leerlo con relativa fluidez), 3) un portugués exclusivamente oral, de fuerte impronta vacacional, abonado por la escucha y el disfrute de numerosos exponentes de la música popular brasileira y, last but not least, para lo que importa especialmente en este artículo, 4) unos conocimientos de alemán ciertamente magros, adquiridos en un par de cursos introductorios, realizados en Buenos Aires unos pocos meses antes de partir hacia mi aventura migratoria, con toda la artificialidad y el carácter excepcional que tiene aprender una lengua en una ciudad donde casi nadie la habla, y donde tampoco "suena" en canciones y programas de televisión. Por demás, esa ignorancia básica venía acompañada también por un vocabulario nada desdeñable (¿50? ¿100 palabras?) de términos especializados de las ciencias sociales y humanas, como todos esos conceptos que en las traducciones que yo había consumido por años solían aparecer destacados en bastardillas o puestos entre paréntesis. De tal forma, se daba la curiosa situación de que en alemán, por un lado, no estaba en condiciones siquiera de emitir frases informativas y muy elementales. $\mathrm{O}$ podía emitirlas, y luego no comprender absolutamente nada de lo que se me contestaba. Pero a la vez podía lanzar al viento expresiones rimbombantes como Seinsverbundenheit des Wissens, en las que palpitaban los corazones de Scheller y de Mannheim, o sustantivosconceptos de alta densidad hegeliano-marxista como Aufhebung, o usar verbos que vistos desde el habla popular de allí suenan rebuscados, pretenciosos o petulantes (como abstrahieren o koordinieren) pero que para mí eran los más fáciles de captar, dada la similitud de estas palabras con las equivalentes en mi lengua materna.

Segunda cuestión: la "escena latina". No lo sabía desde antes de llegar, pero pronto supe que en las grandes ciudades alemanas existía una tan 
nutrida como heterogénea "escena latina" ${ }^{23}$ que, entre otros servicios lúdicos y gastronómicos, podría ofrecerme una especie de refugio existencial al cual podría dirigirme cuando quisiera discurrir unas horas sólo en mi lengua natal. No voy a negar que supe meter un pie dentro del gueto, y alli encontré calor, contención y amistades perdurables hasta hoy. Pero todo aquello supo también causarme alguna asfixia, sobre todo por algunos excesos de idealización teñida de nostalgia que allí imperaban respecto del mundo que habíamos dejado atrás (un mundo que, además, tampoco era exactamente el mismo para todos).

Tercero: a diferencia de lo que sucede en los Países Bajos, o en los países escandinavos, en Alemania no se da un uso generalizado de una segunda lengua que pueda oficiar de puente comunicacional para quienes no manejan la lengua local. En aquellos países es perfectamente posible manejarse en inglés para muchas cuestiones tanto cotidianas como extracotidianas, pero no es el caso en Alemania ${ }^{24}$.

Y cuando, como era mi caso, se añade la pretensión de hacer estudios de posgrado en sociología, a todo lo dicho deben agregársele algunas exigencias adicionales en cuanto a la calidad o intensidad del manejo del idioma, que no tenían que afrontar con el mismo rigor doctorantes en ciencias naturales ${ }^{25}$ ni tampoco mis compañeros y compañeras de la "escena latina" que bailaban, hacian música o se dedicaban a las artes plásticas $^{26}$.

Resumiendo, no sólo para vivir en general una experiencia más plena y gozosa (sin tener que encerrarme en el gueto y sin estar obligado a buscar sucedáneos comunicativos para salir del paso) sino también, más

\footnotetext{
${ }^{23}$ Nutrida: sin llegar a ser tan numerosa como las colectividades procedentes de Turquía, Europa del Este y los Balcanes, la presencia de "latinos" no era ni es insignificante en Alemania. Se trata de una colectividad de inmigrantes bastante activa, y que realiza variadas y bastante visibles manifestaciones políticas y culturales; y heterogénea: porque incluye muy diversos países (a veces también Brasil, y España), ocupaciones, edades/generaciones, etc.

${ }^{24} \mathrm{Al}$ menos no lo era 25 años atrás, cuando todo esto sucedió. No tengo certeza si, entre tanto, esta situación se ha modificado.

${ }^{25}$ Que desde hace décadas tienen el inglés por lengua franca de sus comunicaciones, tanto en las conversaciones cotidianas en el laboratorio como en sus publicaciones y congresos, y que además en su trabajo hacen uso de un idioma muy marcado por el vocabulario técnico, comparativamente más pobre en metáforas y en recursos retóricos que el nuestro de las ciencias sociales.

${ }^{26}$ Dado que ellos y ellas podian recurrir a otro tipo de lenguajes (musicales, corporales, etc.) diferentes de la lengua hablada o escrita, y además eran reconocidos/admirados/buscados e incluso remunerados por ello.
} 
en concreto, para poder hacer un doctorado en sociología en Alemania, yo sentía (y creo que estaba en lo cierto) que no había otro camino que alcanzar un dominio razonablemente amplio y profundo del alemán ${ }^{27}$.

Ahora bien, la lengua en cuestión era justamente el alemán. Además del maravilloso idioma de Hölderlin, Schiller, Goethe, Heine y Brecht, y de Kant, Hegel, Nietzsche, Heidegger, Adorno y Arendt ${ }^{28}$, y de Marx, Simmel y Weber $^{29}$, todo lo cual de por sí ya infunde respeto y admiración, es una lengua bastante difícil de aprender, al menos para quienes venimos del castellano como lengua materna. Si bien la pronunciación nos puede resultar de antemano mucho más sencilla que la del inglés, su gramática es bastante diferente a la nuestra, y en ella abundan las excepciones, por lo cual a veces puede no ser de mucha utilidad el estudio de las reglas. En suma, estaba por sumergirme en la ardua experiencia de aprender una lengua que no tiene la simpleza gramatical del inglés, ni tampoco la similitud léxica de cualquiera de los idiomas derivados del latín.

\subsection{Un aprendizaje formal e institucionalizado}

Es perfectamente posible aprender un idioma extranjero "en la calle", en experiencias informales de la vida cotidiana. En ese caso, en lo que efectivamente termine aprendiéndose quedarán fuertemente adheridas las formas típicas del sociolecto correspondiente al grupo social en cuyo contexto tuvo lugar el proceso. Pero no es ésa la única forma de aprender un idioma. Ello también puede darse a través de procedimientos formales, regulados, en espacios institucionalizados, como un curso, o una serie sucesiva de cursos, dictados en una academia, universidad, o alguna institución por el estilo, con sus docentes especializados, sus ritmos pautados, sus ejercicios, sus exámenes, sus manuales. Lo más habitual es que el proceso de aprendizaje de una lengua extranjera combine y retroalimente ambos espacios, formales e informales. Así fue también en mi caso: viví simplemente la vida en un lugar donde casi todo sucedía en alemán, y

\footnotetext{
${ }^{27}$ La cuestión de la "plenitud" de la experiencia, entiendo que debería seguir vigente. Pero la posibilidad de cursar posgrados en Alemania sin saber alemán ha cambiado significativamente en los últimos años, proceso de Boloña mediante, dado que ahora existe alli una variada oferta académica que se dicta completamente en inglés.

${ }^{28}$ Como se sabe, gran parte de la obra de Arendt fue escrita originalmente en inglés, pero ella nunca dejó de considerarse a sí misma como una hija de la cultura alemana.

${ }^{29}$ Desconozco si los músicos compartirían esta apreciación, pero sería interesante reflexionar si acaso el alemán no es también el idioma que habla en Bach, Beethoven, Brahms y Wagner.
} 
además me inscribí en un curso intensivo de "alemán para extranjeros" o de "alemán como lengua extranjera" en la propia universidad.

Entre tanto ha sido reemplazado por otra certificación, pero por entonces había en todas las universidades alemanas una institución (no exagero al Ilamarla "institución") que infundía una mezcla de temor y respeto entre estudiantes procedentes de otros países/lenguas: el PNDS ${ }^{30}$. Esta sigla significaba literalmente "examen para la demostración de conocimientos del idioma alemán". La aprobación de ese bendito PNDS era un requisito ineludible para poder matricularse en la Universidad. Un curso estaba especialmente previsto para prepararnos para rendir ese examen. Dos semestres, todo muy intenso e intensivo, todos los días, de 9 a 15 horas. Unas docentes (todas mujeres, dato no menor) ${ }^{31}$ con años de experiencia en enseñar este endemoniado idioma a una heterogénea troupe de aspirantes a aprobar el PNDS, pero más allá de eso, también a abrirse paso por los más variados recorridos vitales (muchos preponderante y confesadamente académicos, como el mío; otros no, o no tanto).

Aquella pandilla de aprendices, vista desde hoy, tenía bastante de circense, por lo variopinta y a veces también por lo patética. Es que no deja de producir algo de pena un grupo de adultos balbuceando tonterías, diciendo "yo me llamo..." con un acento incomprensible para casi todo el mundo (incluso para la experimentada profesora), aunque no para los miembros del grupo, que independientemente de nuestras trayectorias previas ${ }^{32}$ buscábamos y encontrábamos entre nosotros nuestra propia y peculiar sintonía. Una chica sevillana de pocas palabras, que se había escapado de un padre brutal y abusador, y yo, éramos los únicos castellanoparlantes del grupo. Por demás, como era de

\footnotetext{
${ }^{30}$ Entre estudiantes extranjeros (por lo general pobres y carentes de automóvil, entre otras tantas carencias) el PNDS era incluso más importante que la licencia de conducir. Desconozco si esto se da este modo también en otros países, pero la obtención de la licencia de conducir tenía en Alemania por entonces un enorme peso simbólico, marcando como una suerte de pasaje a la vida adulta. Los avatares (también idiomáticos, por cierto) que vivi para la obtención de mi licencia alemana de conducir merecerian un artículo aparte.

${ }^{31}$ No tengo datos confiables, sólo impresiones basadas en experiencias propias y ajenas, pero me parece que el trabajo de enseñar un idioma local (cualquiera sea él) a estudiantes adultos y extranjeros se encuentra fuertemente feminizado.

${ }^{32}$ En las que se alojaban desde las cosas que siempre se añoran cuando se está lejos de casa (algunos afectos fundamentales, ciertas comidas, ciertas situaciones, etc.) hasta casos de pobreza extrema, crisis económicas, persecuciones étnicas o políticas y crímenes de guerra.
} 
esperarse, el grupo más numeroso en esa extraña Babel (post)moderna era el de los turcos y turcas en toda la gama de estratos socioculturales, desde hijos de profesionales de clase media alta de Estambul con gafas de diseño hasta pobres campesinos de Anatolia con zapatillas compradas en las rebajas de fin de temporada. Lo seguían en número refugiados diversos de la guerra de los Balcanes, en pacífica aunque tensa coexistencia de bosnios, serbios, croatas, kosovares, etc. También había un egipcio algo mayor que todos nosotros y que por la tarde trabajaba en una carnicería musulmana, un tunecino gay felizmente salido del closet que vestía con mucha elegancia, un chino introvertido y desaliñado a quien jamás pude comprenderle una sola palabra en alemán de las que obligadamente tenía que pronunciar en el curso, un italiano muy simpático que pasó casi todo el año bajo los efectos del cannabis, una polaca detestable que a menudo nos recordaba con evidente arrogancia y sensación de superioridad que ella venía "de Silesia"33, y algunos personajes más que, entre tanto, ya no puedo recordar.

Largas sesiones de ejercicios, conjugaciones de verbos, declinaciones de nominativo, acusativo, dativo y genitivo, alguna que otra película, canciones, más ejercicios, frases y diálogos absurdos que pese a los esfuerzos de nuestras abnegadas profesoras resultaban totalmente descontextualizados y sin sentido, hasta poder retirarnos no sin antes anotar en el cuaderno una larga lista de "tareas para el hogar" para el día siguiente. La faena era realmente ardua, muchas veces dominaba la desazón y la amarga sensación de que el proceso no avanzaba, pero eso no era cierto. Aprender una lengua extranjera no es una tarea aditiva (si en un día aprendo a conjugar diez verbos irregulares, en dos días debería por lógica aprender veinte), sino algo más bien espasmódico, desacompasado. Los progresos efectivos se me revelaban de improviso, al poder solucionar con éxito alguna diligencia burocrática, al captar la sutileza de un aviso publicitario, un juego de palabras o un chiste, al expresar un sentimiento y tener la certeza de que era precisamente "eso" lo que yo quería decir, y que así había sido entendido.

En simultáneo a esta intensa experiencia de aprender alemán, y ante la inminente crisis terminal de mis finanzas, tuve la buena ocurrencia de empezar a enseñar castellano para ganarme la vida. Una tarea

33 "Soy menos extranjera que ustedes", significaba eso. Es que Silesia (o partes de ella) pertenecieron al Imperio Alemán en diferentes momentos de su historia. 
sumamente difícil, para la que no contaba con ninguna capacitación específica, pero que creo no haber hecho tan mal. En efecto, después de todo, algunos de mis alumnos y alumnas terminaron en condiciones bastante buenas para poder leer a García Márquez en su lengua original, para mejorar sus transacciones vacacionales en Mallorca, para hacer un bike tour por las montañas de Ecuador, o para viajar a Buenos Aires a aprender a bailar el tango. Lo cierto es que gracias a este nuevo trabajo, arranqué un vertiginoso y sostenido cambio de roles, de lenguas y de personajes: por la mañana alumno de alemán (acompañado por los ya mencionados compañeros y compañeras) y por la tarde/noche profesor de castellano (con aprendices alemanes tan variados como aquellos, en edades, ocupaciones, intereses y motivaciones para aprender nuestra lengua).

Partiendo de todas estas jugadas pude realizar una importante constatación práctica de algo que yo ya sabía en teoría: la inmensa distancia que hay entre el mero uso de la lengua materna, espontáneo, automático, "natural", y la relativa "artificialidad" implicada en los procedimientos a través de los cuales se la enseña o aprende. De manera que, por razones de mi nuevo oficio, a la obligada consulta permanente de los libros de gramática alemana también debí agregarle los de gramática castellana. Se ponía así en juego un complejo juego de objetivaciones y distanciamientos, en un caso obvio (porque no era mi lengua materna) y en el otro forzado (porque sí lo era y lo sigue siendo): se trataba de re-descubrir la estructura subyacente de mi propio idioma (para poder enseñarlo) y de racionalizar la del alemán (para poder aprenderlo). A su vez, desde mi rol de aprendiz, a ese seco y despojado entrenamiento de manual había que insuflarle algo de "vida". Así, era imperioso poner a funcionar en situaciones reales todo el artificio de las absurdas oraciones de los libros de ejercicios. Y a la inversa, dentro de lo posible y de lo contable en público, tenía que llevar a mis clases de alemán de la mañana lo que había vivido por la tarde $y$, también, por la noche, no sólo enseñando castellano, sino más en general.

\subsection{De la génesis del lector a la obsesión del traductor}

A diferencia de los niños y las niñas, de quienes se sabe que aprenden idiomas extranjeros con pasmosa facilidad y sin mayor necesidad de pasar por la penosa experiencia de estudiarlos, en el caso de personas de edad adulta los esfuerzos deben redoblarse. Más aún si persiguen 
propósitos académicos y, más en concreto, dentro del campo de las ciencias sociales, como era mi caso. Incluso antes de rendir (iy felizmente aprobar!) el tan ansiado PNDS, la rueda de lo que yo podía hacer con las palabras empezó a girar más rápido que al comienzo del proceso, cuando apenas podía balbucear mi nombre luego de decir "yo me llamo".

Los ritmos del leer, el hablar, el escribir, y el entender (la famosa "comprensión auditiva") son siempre desparejos, no se dan en simultáneo. Es posible leer de corrido un idioma y no hablarlo bien, o directamente no hablarlo ${ }^{34}$. Es posible escribir en cierta lengua con mediana corrección, y a la vez tener una comprensión auditiva defectuosa. Y así, todas las combinaciones posibles. Los logros constatables, en mi caso, empezaron siendo de marcado carácter receptivo (leer textos de otros), y no tanto creativo (como escribir textos propios) ${ }^{35}$. De todas formas, leer es también un acto creativo. Deberé explicar con mayor detalle cómo llegué a convertirme en un lector ${ }^{36}$, o en una especie de traductor, y en algunas cosas más.

Harto ya de ejercicios banales y rutinarios, aunque imprescindibles por ejemplo para llegar a comprender entender la decisiva diferencia existente entre "ya" y "todavía no"37, a las pocas semanas de llegar a Alemania me dirigí presuroso a una librería a adquirir una edición barata de Wissenschaft als Beruf de Max Weber, obviamente en alemán. Se trata de un texto riquísimo, que yo había estudiado en detalle en su traducción castellana, donde un Weber maduro, en una conferencia

\footnotetext{
${ }^{34}$ Tal como le pasaba al desgraciado Lazlo Malamüd, el increíble personaje de incidental aparición en La Ciudad Ausente, la novela de Ricardo Piglia (1992). Malamüd era un profesor y crítico literario húngaro, experto en la obra de José Hernández, que emigró a la Argentina luego de la invasión rusa de 1956. "Se sabía el Martín Fierro de memoria, y ese era su vocabulario básico" (ibídem: 16). Pero no sabía hablar el castellano, o hablaba más bien "un idioma imaginario, lleno de erres guturales e interjecciones gauchescas" (ibídem). Así, intentaba desesperadamente aprenderlo, lo necesitaba para poder buscar trabajo de profesor, pero vivía atormentado por "la desesperación que le producía verse condenado a expresarse como un chico de tres años" (ibídem).

${ }^{35}$ A decir verdad, desde el comienzo escribí textos propios en alemán. Por pudor no los reproduzco aquí, aunque tampoco podría hacerlo, pues no los conservé.

${ }^{36}$ El más completo inventario de los sentidos implicados en la pregunta acerca de "quién es el que lee" lo encontré en un maravilloso ensayo de Ricardo Piglia que, precisamente, lleva el título El último lector (2005). Me declaro incapaz de reponer sus argumentos con la belleza, plasticidad y sutileza con que él los escribe, por lo que sólo me limitaré a recomendar fervientemente su lectura.

37 "¿Ha respondido él ya la carta? Sí, él ya ha respondido la carta. No, él todavía no ha respondido la carta". Simplemente traduzco a Dreyer y Schmitt (1985: 79).
} 
pronunciada ante un público de estudiantes ávido de "sensaciones", pincha amargamente el globo de la falsa representación de que el quehacer científico puede otorgarle un sentido al mundo.

Me dispuse a descifrarlo, estimulado con muchas tazas de café y cigarrillos. Conservo todavía ese ejemplar. Por eso puedo decir que la gran cantidad de anotaciones en lápiz que hice sobre él es la prueba empírica más contundente no sólo de la pobreza de mi léxico de aquel entonces, sino también de mi débil comprensión de las estructuras gramaticales alemanas más elementales. Todavía no existían los tan prácticos diccionarios en Internet, ni el tan imperfecto como útil Google Translator. De manera que el viejo diccionario en papel alemán-español y viceversa fue mi más fiel compañero de aquellas aventuras. A falta de uno, tenía dos diccionarios. Uno, más pequeño, como para llevar en la mochila, servía para salir rápidamente del paso, en un caso de urgencia, pero ofrecía una limitada cantidad de acepciones. El otro, mucho más grueso, en dos pesados tomos, era para la biblioteca, para el trabajo reposado, de escritorio. A diferencia del pequeño, ofrecía una variadísima paleta de usos y significados, algo importante cuando se tiene ya un dominio avanzado del idioma (porque permite detectar matices, y pescar entre ellos la palabra más adecuada) pero desesperante para principiantes que buscan una palabra y terminan obligados a buscar muchas otras más.

Aquella fue de las experiencias más difíciles, pero a la vez más gratificantes de todo ese arduo proceso de inmersión en ese nuevo mundo: leer por primera vez en sus versiones originales a algunos de los autores que más me habían impactado durante mis estudios de grado de sociología en Buenos Aires (Marx, Weber y Habermas entre ellos). Y de ese modo, descubrir unos nuevos pliegues específicos de las palabras, unos matices semánticos, unas asociaciones posibles con otras palabras, o unas constelaciones de referencias y citas cruzadas. De todos modos, no siempre se trató de descubrir. Muchas veces, se trató también de re-conocer, re-encontrar y recordar.

Apenas empezar esas lecturas, y a medida que me sentía más seguro al hacerlas, en ese doble juego de descubrimiento y reconocimiento, cai en las garras de una suerte de obsesión por las traducciones, que sigo padeciendo hasta ahora, aunque me enorgullezco de ello, porque creo que le aporta elementos de provecho a mi trabajo. En efecto, me fascinaba observar en detalle cómo estaban hechas las traducciones, 
comparaba traducciones (también traiciones) de diferentes ediciones de la misma obra, en los casos en que las hubiera, y otros ejercicios por el estilo $^{38}$.

De allí en más, el tratamiento específico dado a cada palabra en esa suerte de migración que hacen los textos cuando son resituados de un contexto cultural y lingüístico a otro, el estilo o la "tonalidad" que el autor le quiso imprimir a su voz, las resonancias que todo esto tiene en el lector (y en determinadas comunidades de lectores), esto es, lo que se conserva, lo que se pierde y lo que se gana en estos viajes (de las palabras, pero seguramente debo estar pensando también en las personas que las pronuncian), todo ese conjunto de cuestiones se me volvió desde entonces un foco de atención privilegiado, e incluso un tema de investigación en sí mismo, como luego comentaré.

Pero no se trató solamente de redescubrir en su propia lengua a autores de habla alemana que ya conocía de antes. Así, también me resultó una experiencia fascinante el descubrimiento de autores a los que prácticamente leí por primera vez directamente en alemán, como Luhmann o Simmel ${ }^{39}$. Es decir, realicé de ellos una primera lectura que no estaba "contaminada" por la experiencia previa de las traducciones al castellano, sino que resultó mucho más directa, inmediata, y en cierto sentido "libre". Una consideración crítica de las traducciones disponibles

\footnotetext{
${ }^{38}$ Nadie me lo preguntó, pero igual lo diré: de Das Kapital de Marx, me quedo con la puntillosa y sobria traducción de Pedro Scaron para Siglo XXI, en segundo lugar, la más literaria y florida de Wenceslao Roces para el Fondo de Cultura Económica y en último lugar la de Floreal Mazía para Editorial Cartago (oh sacrilegio, jrealizada desde la versión francesa!). Hay otras, como las publicadas por las editoriales Grijalbo y Akal, pero no las conozco. De la Theorie des kommunikativen Handelns de Habermas, que yo sepa, existe una sola traducción, la que salió primero en Taurus, de modo que el cotejo con otras no me resultará posible (de todos modos, me parece una traducción bastante bien lograda). Finalmente, de la Protestantische Ethik und der Geist des Kapitalismus, de Weber, existen numerosas versiones. Fue decepcionante enterarme que la de Editorial Península, con la que yo había estudiado en la Facultad y que era la que más circulaba, es de las peores. Más tarde, por razones de mi actividad docente (mis estudiantes no suelen saber alemán, pobres de ellos), di con una excelente traducción, lamentablemente muy poco difundida, de Jorge Navarro Pérez para la Editorial Istmo. Y cierro con el viejo y olvidado Tönnies. Su opus magnum, Gemeinschaft und Gesellschaft, tiene dos traducciones. Una más antigua, de 1947, excelente, de José Rovira Armengol, en Editorial Losada, en Buenos Aires, y una con demasiados "problemas", otra vez para Editorial Península, de José Ivars, de 1979. Podría seguir con más ejemplos, pero la nota ha quedado ya demasiado larga. A los fines de lo que quiero ilustrar, es suficiente con esto.

${ }^{39}$ Digo "prácticamente", porque, a decir verdad, sólo algunas pocas cosas de ellos había leído antes en castellano.
} 
de los textos de estos últimos autores llegaría mucho después, ya regresado a la Argentina, y otra vez motivado por las necesidades de la actividad docente.

Hubo además otros síntomas que me dieron a entender que mi grado de inmersión en ese océano lingüístico había ya dejado de ser todo lo elemental que era al comienzo. Esos sintomas se hicieron visibles en el preciso momento en el que descubri que en alemán existen palabras cuya traducción es extremadamente dificultosa ${ }^{40}$. No imposible, por cierto. En última instancia, siempre termina siendo posible hacer alguna traducción, pero en casos como estos no pueden dar en el clavo, no permiten replicar o reproducir (en cualquier caso, no pueden agotar) todos los sentidos que porta consigo el término original. Los sustantivos Stimmung y Heimweh son buenos ejemplos de esto, lo mismo que el adjetivo gemütlich ${ }^{41}$. Hay muchos casos más de esta índole. Otro indicador de inmersión exitosa en esa lengua fue el de descubrir que hay diferentes palabras, con connotaciones o matices también diferentes, que se traducen a una sola palabra en castellano. Buenos ejemplos de esto son Körper y Leib, ambas traducibles como cuerpo ${ }^{42}$, o Erfahrung y Erlebnis, usualmente vertidas como experiencia (aunque en el caso de Erlebnis quizás sea mejor decir vivencia). Finalmente, otro indicador de un grado avanzado de apropiación de la lengua es cuando deja de resultarte sorprendente que, en alemán, haya tres géneros, a lo que se suman curiosidades notables del tipo de que el sustantivo "sol" es femenino, y "Iuna" masculino, así como "puente" es femenino, y "llave" es masculino.

\footnotetext{
${ }^{40}$ En realidad, esto sucede en cualquier lengua, no sólo en alemán, pero yo lo descubrí allí, y los ejemplos que daré serán de allí. Análogamente, Merklen cuenta sus peripecias para traducir al francés una serie de palabras en español importantes para su trabajo (2015: 5).

${ }^{41} \mathrm{~A}$ mi gusto, mood en inglés da mucho más en el clavo de Stimmung, pero estado de ánimo, en castellano, no tanto. Heimweh se parece bastante a la saudade portuguesa, o a la morriña gallega, pero no encuentro palabra que replique el sentido exacto en castellano (quizás lo sea nostalgia). Ahora bien, si Heimweh es de manera aproximada "dolor/nostalgia por el hogar/patria que hemos dejado atrás", ¿qué podría ser Fernweh, siendo el adjetivo/adverbio Fern lejos o lejano en castellano? Y en cuanto a gemütlich, agradable o acogedor podría aproximarse, pero en realidad sigo sintiendo que se trata de "otra cosa".

${ }^{42}$ Quien quiera saber más de esto, puede consultar a Husserl o a Merleau Ponty, que de esto sabían demasiado.
} 


\subsection{Experiencias de escritura}

Una vez que se desborda por primera vez el incuestionable y autoevidente contenedor del vivir y del ser en la lengua que se aprendió en la niñez ${ }^{43}$, se abre un proceso que no termina jamás y que, tal como vengo relatando, incluye sorpresas, placeres y padeceres. Debo admitir que no soy un gran lector de la obra de Wittgenstein, y es por eso que nunca supe a ciencia cierta qué quería decir cuando planteaba aquello de "los límites de mi lenguaje son los límites de mi mundo". Pero si tomo la frase de manera literal, creo que fue exactamente eso lo que generó mi encuentro con la lengua alemana: se me ensanchó enormemente el "horizonte de experiencias" vivibles, pensables y soñables. No se trataba, entonces, solamente de poder leer a Weber (o a cualquier otro autor 0 autora) sin tener que recurrir a traducciones. Había y hay mucho más en juego.

Las diferentes etapas del proceso de inmersión en el idioma alemán fueron quedando sucesivamente atrás, entreveradas, dispuestas de una manera no lineal a lo largo del tiempo. Hasta que llegó un momento en el que quise dar por terminados los prolegómenos y los rituales de preparación, y decidí "pasar al acto" de una buena vez. Dejando de lado toda una serie de cuestiones importantes para la historia y el (buen) desarrollo de mi tesis doctoral (desde establecer contacto con quien sería mi Doktorvater ${ }^{44}$, pasando por formalizar la matriculación en el doctorado en una Universidad diferente a la de donde había aprobado el PNDS, hasta buscar y finalmente obtener una beca que pudiera financiar todo este emprendimiento), y para no desviarme demasiado del propósito del artículo, diré simplemente que este "pasar al acto" implicó empezar a construir con todo esmero un problema de investigación que ya venía rumiando desde tiempo atrás. Luego, se trató de atar un nudo bien denso con muchos hilos, para luego desatarlos, desmenuzarlos y exhibirlos sobre la mesa, y además hacer todo esto por escrito, en formas que de alguna manera se amolden a las convenciones y procedimientos vigentes en el campo pero que al mismo tiempo

\footnotetext{
${ }^{43}$ Lo que en mi caso, además, había sido una sola, a diferencia de los hijos e hijas de extranjeros y extranjeras que suelen vivir en un mundo bilingüe, perfectamente a caballo entre la lengua privada de "la casa" y la lengua pública "del lugar".

${ }^{44} \mathrm{El}$ hecho de que en los países de habla alemana se llame usualmente Dohtorvater (o Doktormutter) a lo que aquí se llama "director/a de tesis doctoral", "advisor" en inglés u "orientador/a" en portugués, merecería una tesis de doctorado, para la que con gusto me ofrecería como director (o como Doktorvater, llegado el caso).
} 
muestren alguna hilacha de la identidad de quien escribe. Todo esto y no otra cosa es, pues, escribir una tesis.

Las tesis en ciencias sociales comparten algunos rasgos con todas las otras tesis: construyen sus problemas y sus preguntas; definen sus objetivos, primero tentativos y luego más firmes; delimitan sus alcances espacio-temporales; revisan y toman posición sobre lo que otros y otras han escrito antes sobre el mismo tema o temas vecinos; prevén procedimientos para hallar "evidencias" que apuntalen o abonen las hipótesis o supuestos que se habían planteado al inicio; analizan esas evidencias; y extraen o infieren conclusiones; además, todo esto debe ser puesto por escrito de manera clara y comprensible. Esto vale para cualquier tesis, insisto.

Es cuestión de gustos, modas intelectuales y tendencias epistemológicas, es siempre opinable y muy discutible, pero no creo estar pecando de excesivo normativismo si sostengo que los trabajos en ciencias sociales y humanas, adicionalmente, tienen que ser elegantes, deben cultivar su estilo literario, si es que pretenden acrecentar su capacidad persuasiva, no sólo convenciendo a sus lectoras y lectores a través de la usual exhibición de evidencias, sino también impresionándolos/as. Y en esto, desde ya, resulta obvio que no es lo mismo si la evidencia es presentada en la forma de tabla, gráfico de barras, o de tarta/torta/pastel, o bien de argumentos con fuertes componentes retóricos, en los que el sonido, o la tonalidad de las palabras deben ser escogidos con el mayor de los cuidados.

Pero me parece que en todo esto no hay en juego sólo razones estéticas/estilísticas, sino también profundas razones epistemológicas y metodológicas. Jablonka explica muy bien la articulación de este juego de razones: "La escritura no es el mero vehículo de 'resultados' ni el paquete que uno ata a las apuradas, una vez terminada la investigación: es el despliegue de esta, el cuerpo de la indagación" (2016: 12). Algo bastante similar, había planteado entre nosotros Zurita unos años antes:

"El proceso de escritura no constituye una actividad inerte ni pasiva en la que sólo se pone por escrito lo previamente observado o, en el mejor de los casos, comprobado, en las diversas visitas a la realidad social. La escritura no es la mera trascripción de la investigación ya realizada y concluida, ni consiste en una etapa posterior, sino que ella forma parte del proceso mismo de la investigación: la escritura es una instancia cognitiva y no tan sólo comunicacional" (2008: 2). 
Siento alta estima y admiración por el sociólogo estadounidense Howard Becker. No practico una sociología que se parezca a la suya, ni por los temas que trabajo, ni por las teorías que uso, ni por los métodos que despliego. Como resulta evidente con sólo leer una página de mi pluma, tampoco sigo al pie de la letra sus consejos a favor de una escritura sociológica "lisa y llana" como la de él. Pero siempre resulta provechoso seguir al menos alguna de sus numerosas pistas de diablo que sabe por diablo, pero que más sabe por viejo. Por ejemplo, la que recomienda poner por escrito los propios pensamientos desde el comienzo del proceso de una investigación. En ese caso, uno "podrá despejar más pronto sus pensamientos. Escribir un borrador sin datos le permitirá ver con mayor claridad lo que desea analizar $y$, por lo tanto, establecer qué clase de información necesita conseguir" (2011: 36). Se trata, en definitiva, "de dar carnadura a las palabras", de "otorgarles realidad física" (2011: 80). Becker no dice nada en particular (al menos, yo no lo he encontrado en sus textos) acerca de los casos en los que esta tarea deba hacerse en una lengua que no es la propia. De todos modos, en estos casos, el provecho de seguir ese consejo es doble. Nunca es fácil despejar los propios pensamientos; al tener que hacerlo en una lengua extranjera, se refuerza el desafío ${ }^{45}$.

Ahora bien, ¿en qué medida en la escritura de mi tesis doctoral estuve a la altura de todos estos requerimientos, en los que se plantea un preciosismo estilístico que a la vez no esté reñido con el rigor metodológico? Creo que en bastante poca medida, pese a que la tesis fue aprobada, y con una buena calificación. No soy exagerado en mi autocrítica, ni quiero pecar de falsa modestia. Sólo esto: todo el proceso de la escritura de mi tesis estuvo atravesado por una perenne (y ciertamente incómoda) sensación: las palabras que estoy en condiciones de escribir (en alemán) nunca llegan a reproducir exactamente lo que pienso (vaya a saberse en qué lengua) ${ }^{46}$. Desde

\footnotetext{
${ }^{45}$ En aquellos años de la elaboración de la tesis todavía no me había encontrado con Becker y sus trucos de viejo sabio (véase no sólo el ya citado 2011, sino también 2009), pero en los primeros meses del proceso me vi obligado por las circunstancias a preparar un "exposé" que debía presentar en un "coloquio de doctorantes", ante la mirada atenta y severa del Dohtorvater. Ese "exposé", con toda su inevitable precariedad, logró no obstante cumplir con creces la importante tarea de darle "realidad física" a las ideas iniciales que sugiere Becker.

${ }^{46}$ Llegó un punto a partir del cual tan nobles actividades como "pensar" o "soñar" las realizaba desde o en (alg)una lengua que no podía identificar con claridad, y que ya no era sólo castellano. Otra vez Merklen, quien como yo fue un "aprendedor" adulto de una
} 
luego, esa sensación puedo también experimentarla en este mismo momento, cuando estoy buscando con denuedo las mejores palabras (en castellano) para plantear mi argumento. Pero aquello fue mucho más extremo. Así, el producto terminó siendo necesariamente modesto, apenas la tesis que pude hacer, y no tanto la que quería hacer ${ }^{47}$.

Sin embargo, fue publicada como libro. En las universidades alemanas es obligatoria la publicación de la tesis para obtener el título luego de la defensa oral (de la llamada Disputatio). Si bien este requisito podía cubrirse a través de cualquier imprenta, en una tirada reducida, quienes me ayudaron en la Korrekturlesen ${ }^{48}$ de la tesis y mi Dohtorvater me insistieron en que probara suerte con editoriales de ciencias sociales. y la tuve. Así, al final de todo ese proceso, apareció un libro de mi tesis en alemán, que hoy por pudor ni siquiera voy a consignar en la bibliografía de este artículo y que, por las mismas razones, nunca quise traducir al castellano ${ }^{49}$.

Pero tampoco se trata de pintar un panorama patético y desesperante, porque en su conjunto realmente no lo fue. El saldo de aquella experiencia fue altamente positivo, y creo haber sido elocuente al respecto. Sería muy injusto restringir mi cosecha de aquellos años en Alemania a un título de doctor, o al conocimiento de primera mano de los méritos y los deméritos de una cultura académica y de un campo

lengua extranjera, sugiere algo con lo que me identifico plenamente: "Una vez salidos de casa, es imposible retornar a la lengua materna como quien vuelve a un espacio natural. La multiplicidad de registros abre asi un espacio de pensamiento 'entre las lenguas' que no pertenece a ninguna de ellas, que surge precisamente de la imposibilidad de pasar inmediata o automáticamente de una a otra, que se nos aparece toda vez que la traducción presenta problema" (2015: 6-7).

${ }^{47}$ En otro ejercicio autoetnográfico/autobiográfico al que me invitaron a escribir pocos meses atrás, había planteado que la modestia de mi tesis doctoral se debía en mayor medida a mi corta edad e inexperiencia ( 29 años al momento de su finalización) que a mis limitaciones en el dominio de una lengua que había aprendido con bastante rigor, pero irremediablemente como adulto (2017: 51). Ahora sigo afirmando lo mismo, aunque enfatizo la cuestión idiomática porque es el tema del presente artículo.

${ }^{48} \mathrm{El}$ proceso de la Korrekturlesen fue otro "hito histórico" importante para la tesis. Sin dinero para contratar estos servicios profesionales especializados, tuve que recurrir a amigos, amigas y colegas de la universidad con buen dominio no sólo de la lengua sino del vocabulario específico, los usos y las costumbres de las ciencias sociales alemanas. La tarea fue ardua, pero provechosa. Lograron pulir al texto de errores imperceptibles para mi, que a menudo se derivaban de meros traspasos al alemán de afirmaciones que, evidentemente, debo haber construido mentalmente en castellano (o inglés, o francés), pero que no admitían una traducción literal.

${ }^{49}$ Desconozco las razones por las cuales, en la última revisión del presente artículo, terminé finalmente morigerando ese pudor. Véase, entonces, de Marinis (2000). 
intelectual fundamental para la historia de la sociología (y no sólo de la sociología). Traje de aquella aventura mucho más, e intentaré decirlo en la siguiente, última sección de este artículo.

\section{SALIDA}

No quisiera pecar de inocente, ni de ignorante, ni me gustaría que se me acuse de tal. Tengo plena conciencia de que todo lo que vengo narrando sucedió precisamente en una geografía cultural donde "el pasado" asume una densidad peculiar ${ }^{50}$, y donde la reflexión (personal y colectiva) sobre el mismo ha adoptado rasgos que pendularon con extrema velocidad entre la represión y el olvido deliberado ${ }^{51}$ y el desgarramiento y la culpa irrefrenable. Las ciencias sociales y humanas jugaron también ese juego, y lo hicieron en algunos casos de maneras dignas y valientes, pero en otros casos también rastreras y miserables, en esa tarea de "hacer algo", o poco, o nada con ese pasado (Aufarbeitung, Verarbeitung, y demás sustantivos, que siempre incluyen Arbeit, trabajo, esto es, algo que no puede ser otra cosa que "trabajoso", pesado, intenso, entreverado, que no fluye ligeramente y sin más).

Desde "adentro", esto es, desde su condición de hablante nativo del alemán (pero también del inglés y del francés), George Steiner fue muy contundente al respecto. En su conocido ensayo "El milagro hueco", escrito durante el apogeo del chato conformismo de la afluencia económica del "milagro alemán", en 1959, pateó sin miramientos el tablero afirmando que "el idioma alemán no fue inocente de los horrores del nazismo" (2013: 127). El italiano Primo Lévi, en la impresionante recuperación de su experiencia en el Lager, habla con mayor ajenidad y distanciamiento del idioma "de ellos", de "los otros". Así, afirma que "a los jóvenes nazis les habían metido en la cabeza que en el mundo había una sola civilización, la alemana; todas las demás, contemporáneas o antiguas, eran aceptables en cuanto contuviesen en sí algún elemento germánico. Por lo cual, quien no entendía ni hablaba alemán era, por definición, un bárbaro" (2000: 80). Victor Klemperer, por su parte, en un libro escrito en condiciones increíbles durante "aquellos

\footnotetext{
${ }^{50}$ ¿Hace falta que diga expresamente que tengo claro que en todas partes "el pasado" asume una "densidad peculiar", pero que "esto" en Alemania es diferente? ¿Hace falta que indique qué parte del "pasado" de Alemania es la que especialmente importa?

${ }^{51}$ Entendidos en el sentido psicoanalítico de "mecanismos de defensa" ante lo intolerable, impensable e inadmisible de la catástrofe civilizatoria acaecida.
} 
años" y que apareció recién en 1947 (2001) se había ocupado de analizar con todo detalle el papel que jugó la lengua alemana en la configuración del pensamiento nazi. Y podría seguir citando libros que exploran estas conexiones entre la lengua alemana y "todo eso" indecible, lo que no puede enunciarse, todo eso ante lo que fracasan las palabras.

En contraste, la reconstrucción de mis experiencias personales (en Alemania, con la lengua alemana) que he hecho en este artículo ha sido más bien leve, pretendidamente jocosa. Sin embargo, todas las densas cuestiones recién comentadas, y traídas de la pluma de Lévi, Klemperer, Steiner y tantos otros y otras están implicadas y supuestas también en ellas. El acceso a una lengua nueva como adulto ya socializado en otra lengua trae consigo sus evidentes dificultades, de las que ya narré algunas. Pero al mismo tiempo quizás permita desplegar una mirada más sensible y menos naturalizada sobre los arbitrios culturales, ideológicos, étnicos, políticos, de género, con los que se cargan las palabras, con los que se crean neologismos, con los que se apuntalan acontecimientos que tienen enormes ( $y$ a veces muy graves) consecuencias prácticas.

Así, el ejemplo del Gastarbeiter, una triste genialidad del idioma alemán para caracterizar, literalmente, a un "trabajador invitado", o "trabajador huésped". Es un término que también se usa de manera general para referirse a extranjeros. Ciertamente amarga es la constatación que debe hacer una persona que lleva muchos años viviendo allí, que hizo de ese país su casa, que procreó allí su descendencia, y que sigue siendo todos los días nominada como "huésped" o "invitada". Porque si eres Gast, entonces no eres de aquí, sino que se te ha cursado una invitación. Y esto es independiente de si has deseado venir (o no). y, en todo caso, si has deseado venir, igual eres un huésped, no alguien de quien se espera que tenga una larga e indefinida permanencia ${ }^{52}$.

\footnotetext{
${ }^{52}$ Cuento por centenas las veces en que, en aquella década en que viví en Alemania, al escuchar mi inconfundible acento extranjero, mis interlocutores lanzaban casi invariablemente esta batería de tres irritantes preguntas (sobre todo la tercera era la que me resultaba más irritante): ¿de dónde eres? ¿qué haces aquí? ¿cuándo piensas volver "a casa"? Con esta última, era evidente que no se referían literalmente a mi hogar, a mi vivienda, al espacio físico donde habitaba, sino a mi respuesta a su primera pregunta ("Buenos Aires, Argentina"). Con el tiempo, pero recién con el tiempo, aprendí a desestabilizar con ironía este interrogatorio. Mis respuestas a las tres preguntas entonces pasaron a ser: "de Schanzenviertel" (el nombre del barrio donde vivía en Hamburgo), "converso contigo", "una vez que terminemos esta conversación, porque estoy algo cansado, pero por suerte vivo aqui cerca".
} 
Ahora no recuerdo si yo disponía de estos saberes y sensibilidades antes de haber vivido estas experiencias, pero quiero creer que luego de tenerlas, y viéndome entonces casi obligado, todo el tiempo, a traducir (palabras, gestos, sentimientos, chistes ${ }^{53}$, etc.), en un sentido o en otro/s, me he tomado mucho más en serio todo lo que se pone en juego en cualquier traducción. Traducción, entonces, que ya no entiendo sólo como la mera actividad técnica de verter una cosa desde un contexto cultural o lengua hacia otro. Sino como algo diferente y mucho más que eso. Como una suerte de astucia, pragmática y existencial, que se funda en un trabajo artesanal con las palabras.

Para ponerlo en términos de los temas de los que me vengo ocupando desde hace unos años en mis investigaciones, esa astucia sirve para darse cuenta de que (y para encontrar interesante explorar las razones por las que) una Gemeinschaft no es precisamente lo mismo que una community, y de que ambas no son una comunidad, ni tampoco una communauté, ni una comunitá ni una comunidade, pero que hay "algo" que no obstante hilvana todas estas palabras, que son también formas particulares de experimentar y connotar el lazo social. Las diversas connotaciones no surgen de un día para el otro en cada lengua. Son el resultado de un largo proceso histórico, que puede reconstruirse al menos parcialmente en sus etapas y sedimentaciones, y en el cual los sentidos se constituyen, se estabilizan, se revierten, cohabitan con otros sentidos, cambian, desaparecen, se pierden, se vacian ${ }^{54}$.

Ya es momento de ir concluyendo, pero no habrá conclusiones, sino apenas el juego de reavivar y reactivar procesos que se abrieron en mi biografía desde aquella experiencia en Alemania y que aún persisten en su andar, y que tienen que ver con una suerte de proclama, consigna, o algo así, que una vez leí en un libro de Boaventura de Sousa Santos, y que me resultó conmovedora. Dice así: "tenemos derecho a ser iguales cada vez que la diferencia nos inferioriza y a ser diferentes cuando la igualdad nos descaracteriza" (2003: 217).

Ya desde la primera fase de aprendizaje cuando luchaba sin descanso contra los molinos de viento de la gramática alemana, creo que, en

\footnotetext{
${ }^{53}$ Esto último, por cierto, con muy poco éxito. No tardé mucho tiempo en descubrir que el humor es una de las cosas menos traducibles que existen.

${ }^{54}$ Ya dije que trabajo desde hace años en torno al concepto de comunidad en la teoría sociológica. Algo de lo que aludía acerca de las distintas semánticas de la comunidad puede verse en de Marinis, 2013.
} 
realidad, simplemente estaba reivindicando mi derecho a ser igual, a ser tratado como tal, a acceder a una suerte de ciudadanía humana básica, elemental, por causa de la cual nadie podría darme a entender que yo no estaba en "mi casa" (aunque esto viniera de la mano de la pregunta, aparentemente inocente, pero implacable, de cuándo volvería a "mi casa", suponiendo implícitamente que esta no lo era).

Con todo esto en juego, no se trataba solamente de entender a "Ios alemanes", a sus maravillosas creaciones culturales y a las catástrofes históricas que habian desencadenado, sino también de entablar diálogo con todos los demás extranjeros (excepto "Ios latinos") con quienes el alemán pasó a ser para mí el único y gran vehículo de comunicación.

Por supuesto, además de hacer estos esfuerzos de "igualación", en los que a veces tuve éxito y a veces no, también sentí la necesidad de desplegar otras tantas estrategias de "diferenciación" ${ }^{55}$ contra la "descaracterización" que las sociedades receptoras siempre tienden a ejercer sobre sus migrantes al momento de nominarlos y subsumirlos, sin más, bajo la desdiferenciadora aunque objetiva categoría de "inmigrantes", "extranjeros", pero también bajo otras denominaciones menos neutrales o más peyorativas y prejuiciosas, o profundamente controvertidas.

Haber podido cargar en la mochila de mi vida todas estas experiencias, estas percepciones, estas sensaciones y estas sensibilidades de la igualdad y la diferencia, creo que es el más duradero saldo que me han dejado aquellos años en Alemania en los que, además, hice un doctorado en Soziologie (que más o menos es lo mismo que sociología, sociology, sociologie, pero diferente).

\section{Bibliografía}

Araujo, K. (2015). Culturas académicas: entre reinvención y contrabando. Papeles del CEIC. International Journal on Collective Identity Research, 2015/1(118), 1-17.

Arocena, F. (2015). La mirada del otro. Breve autoficción intelectual. Papeles del CEIC. International Journal on Collective Identity Research, 2015/1(120), 1-18.

\footnotetext{
55 "Diferenciación" no necesariamente y siempre tiene que ver sólo con "oponerse". Puede tener también alguna relación con la decisión y el acto de "reinventarse". Ver en qué sentidos Araujo (2015) se refiere a sus experiencias migratorias como "reinvención".
} 
Becker, H. (2009). Trucos del oficio. Cómo conducir su investigación en ciencias sociales. Buenos Aires: Siglo XXI.

Becker, H. (2011). Manual de escritura para científicos sociales. Cómo empezar y terminar una tesis, un libro o un artículo. Buenos Aires: Siglo XXI.

Beigel, F., Gallardo, O., y Bekerman, F. (2018). Institutional Expansion and Scientific Development in the Periphery: The Structural Heterogeneity of Argentina's Academic Field. Minerva. A Review of Science, Learning and Policy, 1, 1-27. https://doi.org/10.1007/s11024017-9340-2

Blanco, A., y Wilkis, A. (en prensa). The Internationalization of Sociology in Argentina, 1985-2015: Geographies and Trends. En J. Heilbron, G.Sorá y T. Boncourt (Eds.), The Social and Human Sciences in a Global Perspective. London: Palgrave.

Blanco, M. (2012). Autoetnografía: una forma narrativa de generación de conocimientos. Andamios. Revista de Investigación Social, 9/19, 4974.

Blois, J. (2014). El mercado de trabajo de los sociólogos en Argentina desde la vuelta de la democracia. El caso de los graduados de la UBA. Trabajo y Sociedad, 22, 103-122.

Blois, J. (2018). Medio siglo de sociología en la Argentina. Ciencia, profesión y política (1957-2007). Buenos Aires: Eudeba.

Castillejo Cuéllar, A. (2015). Utopía y desarraigo. Papeles del CEIC. International Journal on Collective Identity Research, 2015/1(121), 130.

Deleuze, G. (1995). Post-scriptum sobre las sociedades del control. En Conversaciones 1972-1990 (pp. 277-286). Valencia: Pre-Textos.

de Marinis, P. (2000). Überwachen und Ausschließen. Machtinterventionen in urbanen Räumen der Kontrollgesellschaft. Pfaffenweiler: Centaurus Verlagsgesellschaft.

de Marinis, P. (2013). Gemeinschaft, community, comunidad: algunas reflexiones preliminares acerca de las variadas semánticas de la comunidad en la teoría sociológica. Revista Argentina de Ciencia Política, 16, 87-104.

De Sousa Santos, B. (2003). La caída del Ángelus Novus: ensayos para una nueva teoría social y una nueva práctica política. Bogotá: ILSA.

Dreyer, H., y Schmitt, R. (1985). Lehrund Übungsbuch der deutschen Grammatik. München: Verlag für Deutsch. 
Feliu, J. (2007). Nuevas formas literarias para las ciencias sociales: el caso de la autoetnografía. Athenea Digital, 12, 262-271.

Francescutti, P. (2015). Una mirada casi distante. Papeles del CEIC. International Journal on Collective Identity Research, 2015/1(119), 1-16.

Gatti, G., Irazuzta, I., y Martuccelli, D. (2015). Fuera de campo. Trayectorias e identidades de investigadores latinoamericanos hoy. Papeles del CEIC. International Journal on Collective Identity Research, 2015/1(intro), 1-7.

Gatti, G. (2015). Entre parásitos y ausentes. Paseo figurativo por el campo (intelectual) latinoamericano. Papeles del CEIC. International Journal on Collective Identity Research, 2015/1(115), 1-16.

Irazuzta, I. (2015). Tres vértices atlánticos: perfiles, dislocaciones y paralaje. Papeles del CEIC. International Journal on Collective Identity Research, 2015/1(117), 1-24.

Jablonka, I. (2016). La historia es una literatura contemporánea. Manifiesto por las ciencias sociales. Buenos Aires: Fondo de Cultura Económica.

Jitrik, N. (1969). Los viajeros. Buenos Aires: Editorial Jorge Álvarez.

Klemperer, V. (2001) [1947]. LTI: La lengua del Tercer Reich. Apuntes de un filólogo. Barcelona: Minúscula.

Lévi, P. (2000) [1986]. Los hundidos y los salvados. Barcelona: Muchnik.

Martuccelli, D. (2015). Cartografía y horizontes de la sociología sobre América Latina. Papeles del CEIC. International Journal on Collective Identity Research, 2015/1(114), 1-33.

Merklen, D. (2015). En alguna parte del mundo. Montevideo, Buenos Aires, Paris. Papeles del CEIC. International Journal on Collective Identity Research, 2015/1(116), 1-21.

Offe, C. (2006). Autorretrato a distancia. Tocqueville, Weber y Adorno en los Estados Unidos de América. Buenos Aires: Katz Editores.

Piglia, R. (1992). La ciudad ausente. Buenos Aires: Sudamericana.

Piglia, R. (2005). El último lector. Barcelona: Editorial Anagrama.

Schrecker, C. (Ed.) (2010). Transatlantic Voyages and Sociology. The Migration and Development of Ideas. Aldershot: Ashgate.

Steiner, G. (2013). Lenguaje y silencio. Ensayo sobre la literatura, el lenguaje y lo inhumano. Barcelona: Gedisa.

Zurita, C. (2008). El bloqueo de la página en blanco. Notas sobre la sociología como género literario. Trabajo y Sociedad, 10, 1-10. 